ISSN electrónico: 2172-9077

DOI: https://doi.org/10.14201/fjc202123293296

\title{
ARTES ENTRE ARTES
}

\section{Arts between arts}

Dr. David PÉREZ ÁLVAREZ

Profesor IES PINO MANSO, España

E-mail: dperal@edu.xunta.gal

(iD https://orcid.org/content/initiative?locale_v3=es

Fecha de recepción de la reseña: 1/10/2021

Fecha de aceptación definitiva: 7/10/2021

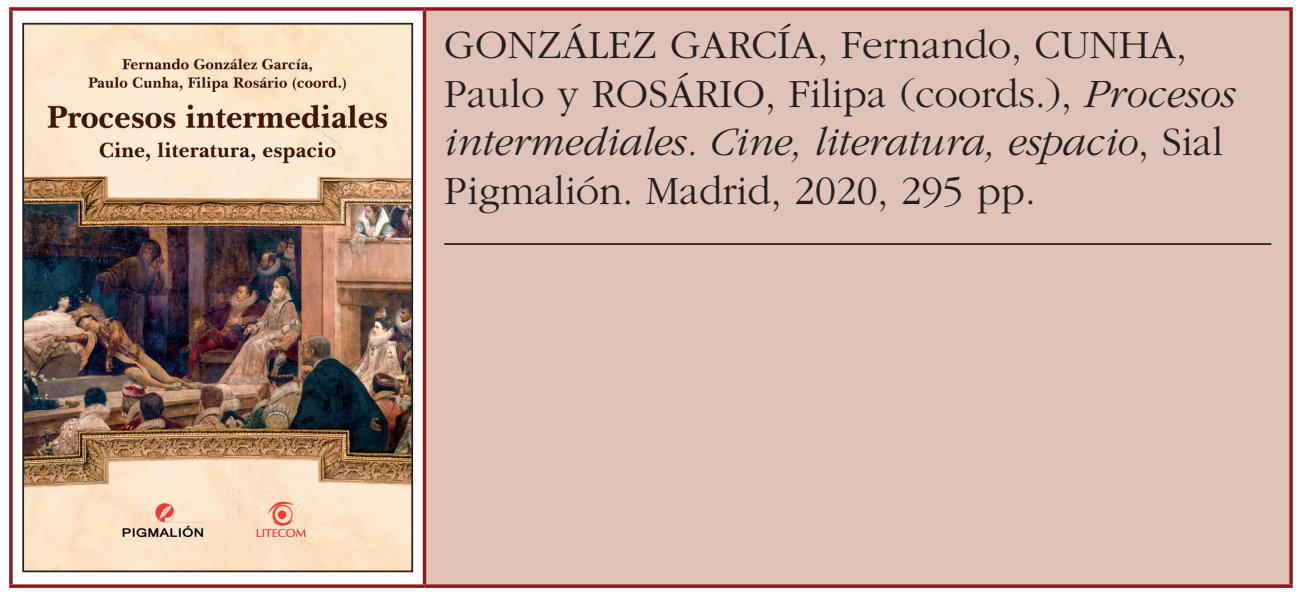

Procesos intermediales. Cine, literatura, espacio, coordinado por Fernando González García, Paulo Cunha y Filipa Rosário, reúne una serie de artículos que evidencian la necesidad actual de ver el arte como un fenómeno intermedial, de continuos trasvases entre obras pertenecientes a distintos soportes que condicionan tanto la recepción como la propia creación. El resultado es un rico panorama que establece vínculos de muy diverso orden entre cine, teatro, literatura, danza, artes performativas, crítica literaria... Si, de acuerdo con Masgrau-Juanola y Kunde (2018, p. 623), la "crítica intermedial genera herramientas para abordar productos artísticos y culturales singulares desde un punto de vista sincrónico, pero también es útil en su enfoque diacrónico, para entender cómo cristalizan los nuevos géneros», el presente trabajo atiende a ambos fines, en la medida en que, aunque predomine el enfoque sincrónico, hay también artículos que abordan el fenómeno desde el punto de vista diacrónico. El volumen, por tanto, resulta de gran interés tanto para quienes estén interesados en 
autores y obras particulares como para quien desee indagar a nivel teórico o crítico en modelos de análisis comparado que permiten captar en toda su complejidad los mecanismos intermediales.

En primer lugar, José Antonio Pérez-Bowie analiza la paralela evolución del teatro y el cine por caminos vanguardistas que los alejan de sus fundamentos tradicionales. De esta manera, nos muestra las estrategias a través de las cuales el teatro prescinde del drama y el cine de la narración, dando mayor peso a otros aspectos como, por ejemplo, el trabajo físico actoral en el caso del teatro o la imagen como objeto estético autónomo en el caso del cine. Asimismo, señala Pérez-Bowie el intercambio de elementos entre ambos medios como otro recurso que los impulsa hacia lugares ajenos a los cauces artísticos habituales. Se trata de un interesante recorrido que nos muestra hasta qué punto hay una suerte de hermanamiento entre ambas artes en su afán de renovación.

Seguidamente, Annalisa Mirizio traslada el concepto de ilegibilidad artística, desarrollado por Túa Blesa en el campo de la literatura, al campo cinematográfico, y más concretamente al caso de director y dramaturgo italiano Carmelo Bene, lo cual resulta ser altamente productivo a nivel crítico-teórico. Tras explicar, centrándose en la particular actitud de Bene, los fundamentos e implicaciones de esta ilegibilidad, la ruptura con la búsqueda de sentidos referenciales, la reivindicación de una vida artística distinta e independiente de la vida orgánica, la negación de la función comunicativa del arte y la anulación del público, localiza y desgrana los factores de elegibilidad de cinco películas de Bene: Nostra Signora dei Turchi, Capricci, Don Giovanni, Salomè y Un Amleto di meno.

Ana Isabel Soares estudia los vínculos entre poesía y cine en Pier Paolo Pasolini y Antonio Reis. Respecto al primero, aborda su concepto teórico de "cine de poesía», en tanto que centrado en el estilo, en la imagen, y la fuerte unidad que el propio autor reconocía entre este tipo de cine y la poesía escrita. Para ello, analiza los versos de su poema "Who is me: poeta de las cenizas", incidiendo en aquellos pasajes de carácter visual o escénico que poseen mayor carácter cinematográfico. En cuanto a Antonio Reis, se adentra Soares en la paradoja de que, desde el género documental, pueda lograr un "cine de poesía" como el que apuntaba Pasolini, y reflexiona acerca de la manera en que el artista trató de recrear la realidad la deprimida región de Trás-os-Montes, primero a través de la fotografía, a continuación a través de la poesía, y finalmente mediante el cine documental, tratando de alcanzar en cada medio un punto mayor de autenticidad.

Por su parte, $\mathrm{M}^{\mathrm{a}}$ Teresa García-Abad nos acerca a la figura de Max Ophüls, poniendo de manifiesto la importancia que tuvo para su labor como cineasta su experiencia como actor y sobre todo como director teatral, desde una concepción antinaturalista que daba primacía a la experimentación con diversos recursos escénicos y actorales más allá de la palabra, profundizando especialmente en la conexión de las puestas en escena de Ophüls con las nuevas concepciones teatrales que buscaban escenarios más dinámicos. Asimismo, señala la existencia de estrategias cinematográficas vinculadas con el tópico del theatrum mundi, con el que el director alemán busca reflejar el mundo de vanas apariencias de la Viena de entresiglos. Por último, dedica un apartado a Lola Montes, película en la que cobra protagonismo el espacio circense, en conexión con el gusto de las vanguardias por espectáculos de raíz popular en los que el público-masa participaba como de un ritual festivo. 
Jorge Palinhos toma como objeto de investigación la obra de teatro O Crime de Aldeia Velha, de Bernardo Santareno, su puesta en escena a cargo de António Pedro y la versión cinematográfica de Manuel Guimarães, y realiza un análisis comparado focalizado en el espacio. En su estudio de los elementos espaciales, Palinhos recorre aquellos motivos que reflejan la opresión social y el peso de la religión católica, mostrando cómo la puesta en escena de Antonio Pedro y la versión cinematográfica de Manuel Guimarães dieron a la obra de Santareno una carga simbólica que guarda notables tensiones con su cariz nítidamente realista y naturalista, contraste que tuvo repercusiones negativas en la recepción crítica de las obras.

En el trabajo de Paulo Cunha, encontramos una indagación en las relaciones del cine portugués con la Guerra Civil española desde la época de Salazar hasta la actualidad. Observa Cunha cómo durante el Estado Novo productoras portuguesas llevaron a cabo un ejercicio de propaganda franquista a través de documentales pronacionalistas, destacando el caso de Aníbal Contreiras. A continuación, se centra en la figura del escritor Jorge de Sena para tratar la adaptación cinematográfica de dos obras suyas vinculadas al conflicto español, desde una perspectiva de denuncia antifascista: Os salteadores, dirigida por Abi Feijó, y Sinais de Fogo, a cargo de Luís Filipe Rocha. Por último, aborda la reciente adaptación de la novela de Saramago O ano da morte de Ricardo Reis, a cargo del director João Botelho, así como el también reciente cortometraje Noite perpetua, de Pedro Peralta, basado en la historia real de una maestra exiliada.

Iván Villarmea Álvarez, tras ofrecer un panorama internacional de películas de encierro de distintas épocas, hace una cala en la cinematografía española previa a la pandemia que mostraba situaciones de encierro relacionadas con la crisis económica de 2008, y las analiza como una suerte de anticipo del posterior confinamiento a que nos obligaría la pandemia COVID, así como un reflejo de los problemas que acucian a nuestra sociedad. Para ello, propone una clasificación en películas distópicas, películas que abordan la problemática de los jóvenes que ven imposible emanciparse o deben regresar a la casa familiar, películas en las que los personajes se recluyen a modo de refugio o huyen en busca de la libertad y, por último, películas en las que se justifica el encierro con metas creativas que terminan cayendo en el vacío.

Beatriz Leal Riesco dedica su artículo a 12 Years a Slave, de Steve McQueen, y su tratamiento de la esclavitud negra en los EE.UU. anteriores a la Guerra de Secesión, en conexión con un concepto de alienación más universal que entroncaría con situaciones provocadas por el actual sistema capitalista. De esta manera, y contextualizando dicha película en la trayectoria del cineasta, así como en la situación real, autobiográfica, de Solomon Northrup, cuyas memorias está adaptando, analiza el uso de determinados afrotropos vinculados a la identidad diaspórica africana y lleva a cabo una detallada interpretación de algunas de las escenas más significativas del filme.

Javier Sánchez Zapatero nos acerca a las diversas ramificaciones del universo creado por Vázquez Montalbán en su serie de novelas protagonizadas por Pepe Carvalho. En primer lugar, trata las adaptaciones cinematográficas y televisivas, que hacen del detective por lo general un elemento instrumental y dan cada una versión y una imagen muy dispares. En segundo lugar, aborda la adaptación al cómic a manos de Seguí y Migoya, apuntando la gran fidelidad con la que reproducen el universo de Carvalho y la Barcelona retratada por el escritor, y analizando la forma en que combina el género negro con el estilo del cómic europeo. Por último, estudia la continuación, dentro del mismo soporte literario, de las historias de Carvalho a cargo de Carlos Zanón, 
señalando cómo mantiene elementos esenciales de este universo pero adaptándolo a su propio estilo y trasladándose al siglo XXI mediante un juego metaficcional.

Fernando González García toma como objeto de estudio la creación/participación de John Berger en obras pertenecientes a distintos medios y relacionadas todas ellas con las cuevas de Chauvet y sus pinturas paleolíticas: textos de carácter ensayístico, la instalación artística The Vertical Line y el documental Dans le silence de la grotte Chauvet, dirigido por Pierre-Oscar Lévy, pero en el que participa ante las cámaras el artista del que trata este artículo. De esta manera, González García analiza cómo la figura de Berger opera intermedialmente para expresar, en una obra dispersa pero coherente, la singular relación del cuerpo con las imágenes, los referentes y las palabras en el proceso artístico.

Por último, Ana Bela Morais centra su atención en Hable con ella, de Pedro Almodóvar. La contextualiza en la producción del director manchego en una etapa en la que se vio fuertemente influido por el género melodrámatico, y señala cómo esta película se dedica en realidad a subvertir o invertir elementos habituales del género, sobre todo en lo que respecta a los roles masculino y femenino. Por otro lado, se detiene en los recursos utilizados para representar simbólicamente el deseo y la violación, así como en el potencial significativo de determinadas estrategias metaartísticas (el cine dentro del cine, la danza dentro del cine). Asimismo, muestra la importancia que adquiere en la película el cuerpo femenino, capaz de erigirse en motor expresivo y narrativo por sí solo, sea en movimiento, sea en el reposo del coma en el que han caído las protagonistas.

En definitiva, nos encontramos ante un volumen variado, por la diversidad de obras, géneros y medios tratados, pero sumamente coherente y bien articulado, orientado por una mirada abierta y atenta a la complejidad interartística, mirada común a todos los colaboradores de este proyecto, que con sus perspicaces calas críticas y teóricas dan cuenta de la riqueza que aporta la intermedialidad a unos materiales artísticos en constante evolución, a la vez que constatan la idea de que, actualmente, y en palabras de Sánchez-Mesa y Baetens (2017:6), el comparatismo ya no se puede "restringir a elementos lingüísticos o verbales», sino que exige un «enfoque más basado en la categoría de medio". La lectura, en fin, de Procesos intermediales. Cine, literatura, espacio, nos hace conscientes del intenso dinamismo que caracteriza a las artes de los siglos XX y XXI abocadas a convivir con tal multiplicidad de medios y a saber interconectarlos.

\section{Bibliografía}

Masgrau-Juanola, Mariona y Karo Kunde (2018). La intermedialidad: un enfoque básico para abordar fenómenos comunicativos complejos en las aulas. Arte, Individuo y Sociedad, 30 (3), pp. 621-637 (disponible en https://revistas.ucm.es/index.php/ARIS/article/ view/59812/4564456548054).

Sánchez-Mesa, Domingo y Jan Baetens (2017). La literatura en expansión. Intermedialidad y transmedialidad en el cruce entre la Literatura Comparada, los estudios culturales y los New media studies. Tropelías. Revista de Teoría de la Literatura y Literatura Comparada, 27, pp. 6-27 (disponible en https://dialnet.unirioja.es/servlet/articulo?codigo=5790815). 